\title{
Extraction, Characterization, and Utilization of Shrimp Waste Chitin Derived Chitosan in Antimicrobial Activity, Seed Germination, Preservative, and Microparticle Formulation
}

\author{
Abirami S ${ }^{1 \mathbb{D}}$, Nagarajan $\mathrm{D}^{2}$, Antony V Samrot ${ }^{3, * \mathbb{D}}$, Mini Varsini A ${ }^{1}$, Sugasini A ${ }^{1}$, \\ Daniel Alex Anand ${ }^{4}$ \\ 1 Department of Microbiology. Kamaraj College of Arts and Science, Thoothukudi, Tamil Nadu - 628003, India \\ 2 Department of Zoology. Kamaraj College of Arts and Science, Thoothukudi, Tamil Nadu - 628003, India \\ 3 School of Bioscience, Faculty of Medicine, Bioscience \& Nursing, Jalan SP 2, Bandar Saujana Putra, Jenjarom, 42610, \\ Selangor, Malaysia \\ 4 Department of Bioinformatics and the Centre for Molecular Data Science and Systems Biology, Sathyabama Institute of \\ Science and Technology, Chennai - 600119, India \\ * Correspondence: antonysamrot@gmail.com;
}

Scopus Author ID 36100751800

Received: 6.06.2020; Revised: 2.08.2020; Accepted: 5.08.2020; Published: 8.08.2020

\begin{abstract}
In this study, chitosan was obtained from the chitin of shrimp waste. It was further purified, and the degree of acetylation was measured by FTIR and NMR analysis. Further, it was subjected to antimicrobial activity against wound infection-causing bacteria and phytopathogenic fungi. It was showing good activity against both. It was used as a preservative for grape juice, where it was decreasing the turbidity. The chitosan had seed germination activity on paddy seed. Chitosan was subjected for the formation of chitosan film and subjected for antifungal activity against phytopathogenic fungi, thus used as a preservative on wrapping tomato. It was increasing the shelf life of the tomato. Chitosan was also used for microparticle formulation, where it was able to form microparticles of size about $100 \mu \mathrm{m}$ and it possessed antifungal activity.
\end{abstract}

Keywords: chitosan; degree of deacetylation; antimicrobial activity; chitosan film; preservative.

(C) 2020 by the authors. This article is an open-access article distributed under the terms and conditions of the Creative Commons Attribution (CC BY) license (https://creativecommons.org/licenses/by/4.0/).

\section{Introduction}

Chitosan is made of $\beta$ 1,4-linked glucosamine, and it is in deacetylated form of chitin obtained from fungi, shrimps, crab, etc. [1-3]. Chitosan has been used as a biomaterial, pharmaceutical, drug delivery [4], medical [5], textile [6], agricultural [7], preservative [8], wastewater purification [9,10], plant pesticide [11], and dressing material for wounds [5]. Chitosan is known to have antibacterial activity, thus used in making loves, wound bandages, textiles, etc. [12].

The presence of an amino group helps in forming various structures on reacting with TPP (trisodium polyphosphate) or $\mathrm{BaCl}_{2}$ (barium chloride). Thus manipulation is possible and leading to have different solubility, physical, mechanical properties, and enhance biocompatibility [1,13]. Polymers seen on chitosan are made of $\mathrm{N}$-acetyl glucosamine and glucosamine, which has been known to have better biocompatibility and biodegradability, adding more it has the flexibility to form gels when proper polyanions are used [14.15]. There are reports of using this chitosan as a source of protecting seeds on coating by having fungicidal 
activity [16]. The present study, chitosan, was obtained from shrimp and used was to evaluate the enhancement effect of antimicrobial properties of chitosan, preservative property, and also utilized for microparticle synthesis.

\section{Materials and Methods}

\subsection{Materials.}

Crude chitin obtained from shrimp [17], Tripolyphosphate $\left(\mathrm{Na}_{5} \mathrm{P}_{3} \mathrm{O}_{10}\right)$, Dithiothreitol were obtained from Sigma chemicals, India. Acetic acid was of analytical grade. Mueller Hinton Agar (M173) was from HiMedia, Bombay, paddy seed bought from TNAU, Vallanadu, Tirunelveli.

\subsection{Deacetylation of chitin.}

The prepared dried crude chitin [18] was used for the chitosan preparation as described [19]. $1 \mathrm{~g}$ chitin / $50 \mathrm{~mL}$ of $50 \% \mathrm{NaOH}$ for deacetylation and mixed at $100{ }^{\circ} \mathrm{C}$ under constant manual stirring. This was done for $3-5 \mathrm{~h}$. It was subjected to filtration using a muslin cloth, and solid mass obtained was washed with distilled water till it becomes neutral. It was collected and at $80^{\circ} \mathrm{C}$ overnight.

\subsection{Purification of chitosan.}

Prepared chitosan was dissolved with $1 \%$ acetic acid (0.01:1 - chitosan : acetic acid) and stirred in a magnetic stirrer until a homogenous solution was obtained. The solution was filtered with Whatman filter paper No.1 to remove the insoluble contaminants. The obtained solution was again added with $1 \mathrm{~N} \mathrm{NaOH}$ until it reached a $\mathrm{pH}$ of 8.5 to precipitate chitosan, following the washing with distilled water (subjecting for centrifugation at 10,000 rpm). Reducing agent DTT (Dithiothreitol) was used since it was used for biomedical applications. $1 \mathrm{~mL} 10 \%$ sodium dodecyl sulfate (SDS) to precipitate, which was stirred for 15 - 30 min to dissolve proteins and kept undisturbed in room temperature for $12 \mathrm{~h}$, now $5 \%$ EDTA was added to remove heavy metals. Thus it was kept for $2 \mathrm{~h}$. Now the undissolved chitosan was centrifuged at $6000 \mathrm{rpm}$ for $15-30 \mathrm{~min}$, followed with washing with distilled water for thrice. The obtained residue was dried at $60{ }^{\circ} \mathrm{C}$, followed with desiccation, and then stored in $4{ }^{\circ} \mathrm{C}$ [20].

\subsection{Characterization of chitosan.}

\subsubsection{FT-IR}

The chitosan was subject to Fourier transform spectrophotometer analysis (IFS 66 Bruker) in the infrared spectral region between 400 and $4000 \mathrm{~cm}^{-1}$. Degree of deacetylation was determined according to the equation described by Domszy and Roberts [21] as per the given formula

$$
\mathrm{DD}=\frac{100-\left(A 1660 \mathrm{~cm}^{-1} / A 3450 \mathrm{~cm}^{-1}\right)}{1.33} \times 100
$$

\subsection{2. ${ }^{1} \mathrm{H}$ NMR spectroscopy.}

0.05 g prepared chitosan was mixed with deuterated aqueous acid $\mathrm{DCl} / \mathrm{D}_{2} \mathrm{O}$, at about $\mathrm{pH} 4$, where the conditions were followed as specified. A spectrum of the shrimp shell derived 
chitosan result was compared with that of standard chitosan [22]. The degree of deacetylation was determined.

\subsubsection{Other characterization.}

Percentage moisture content[23]. Ash value [24], \% Water Binding Capacity (WBC), and \% Fat Binding Capacity (FBC) of chitosan [25] was also performed.

\subsection{Applications of chitosan.}

2.5.1. Antibacterial activity against wound pathogens.

Chitosan dissolved in $1 \%$ of acetic acid and used for further studies [26]. Wound isolates (Gram-negative isolates - Escherichia coli, K. pneumoniae, P. aeruginosa, and Grampositive isolate - Staphylococcus aureus) were used in this study. The agar well diffusion method was adopted for the antibacterial assay [27]. Minimal inhibitory concentration and Minimum Bacterial Count (MBC) values of chitosan against the test pathogens were performed [28].

\subsubsection{Antifungal activity.}

Antifungal activity was studied against plant pathogenic fungi like Mucor sp., Fusarium sp., and Aspergillus sp. using mycelial growth inhibition assay as described by Wang et al. [29]. Inhibition reaction was obtained by using the following formula:

$$
\text { Inhibition ratio }(\%)=\frac{\mathrm{C}-\mathrm{E}}{\mathrm{C}} \times 100
$$

Where, $\mathrm{C}=$ Growth of pathogen in the control plate $(\mathrm{mm})$ and $\mathrm{E}=$ Growth of pathogen in experimental plates $(\mathrm{mm})$

\subsubsection{Preservative activity against grape juice.}

Grapefruits were bought from a local market, washed with tap water, and made into juice using a blender, filtered using a sieve, and then stored at $4{ }^{0} \mathrm{C}$ for the study. Clarification of grape juice was done adding chitosan $(1 \%, 1.5 \%$, and $2 \%$ / L of prepared juice). Grape juice samples were flocculated at $35{ }^{\circ} \mathrm{C}$ for $30 \mathrm{~min}, 60 \mathrm{~min}$, and $90 \mathrm{~min}$, then subjected for centrifugation at $6000 \mathrm{rpm}$ for $20 \mathrm{~min}$. Juice obtained was read at $540 \mathrm{~nm}$ [30]. Quality was assessed at regular intervals by analyzing its $\mathrm{pH}$, Microbiological examination [31] for a total count of bacteria and mold count at regular intervals.

\subsubsection{Algicidal activity.}

The algicidal activities of the chitosan were investigated by inoculating $99 \mathrm{ml}$ of representative exponentially growing Chlorella sp. culture with $1 \mathrm{ml}$ of the chitosan solution $(1 \%, 1.5 \%$, and $2 \% \mathrm{w} / \mathrm{v}$ in $1 \%$ acetic acid). In control, $1 \mathrm{ml}$ of $1 \%$ acetic acid was used [32].

\subsubsection{Seed treatment experiment of chitosan.}

A $2 \%, 1.5 \%$ and $1 \%$ chitosan solution was prepared in $1 \%$ acetic acid, after absolute mixing, the $\mathrm{pH}$ was made to $7 \mathrm{using} 12 \% \mathrm{NaOH}$. Two groups were used (each with 150 paddy seeds). Control (received no treatment - but dipped in $1 \%$ acetic acid for $12 \mathrm{~h}$ ) and tests were coated with different concentrations of chitosan $(2 \%, 1.5 \%$, and $1 \%)$ by soaking the seed in 
a respective solution for $12 \mathrm{~h}$. They were dried at room temperature for $24 \mathrm{~h}$, which enhances the coating of chitosan [33]. Germination was determined as detailed in ISTA [34]. 50 seed/dish was introduced and incubated under controlled conditions with a photoperiod of 12 $\mathrm{h}$ and $85 \%$ relative humidity). Germination percentage (GP) was explored after $7^{\text {th }}$ day [35].

\subsubsection{Preparation of chitosan films.}

$50 \mathrm{~mL}$ of $1 \%$ and $2 \%(\mathrm{w} / \mathrm{v})$ chitosan was mixed with $50 \mathrm{~mL}$ of $10 \%$ polyvinyl alcohol solution respectively and heated at $100{ }^{\circ} \mathrm{C}$ with constant stirring to get a homogenous mixture. To this mixture, $10.55 \mathrm{ml}$ of glutaraldehyde reagent was added, stirred slowly for $14 \mathrm{~h}$, care was given to stop the formation of air bubbles while casting, it was allowed for drying at room temperature for $84 \mathrm{~h} \mathrm{[36].}$

\subsubsection{Antimicrobial activity of chitosan films.}

Agar diffusion method was followed to study antibacterial activity against Salmonella sp., Escherichia coli on Mueller Hinton agar [37] and the chitosan films $(1 \mathrm{~cm})$ of $1 \%$ and 2 $\%$ were placed on the surface of the plates, and plain films that lack chitosan were prepared and used as control. The plates were incubated for $37{ }^{\circ} \mathrm{C}$ for $24 \mathrm{~h}$. After incubation, the zone of inhibition was measured on the basis of the average diameter of the clear area. Likewise, the antifungal property of chitosan films was determined by swabbing spore of fungi - Aspergillus sp. on Rose Bengal agar plates.

\subsubsection{Chitosan films as wrappers for extending the shelf life of food.}

Six fresh tomatoes were taken, washed in running tap water, and dried room temperature to make sure no moisture on the skin. One set ( 3 tomatoes) and another 3 tomatoes (experimental set) were covered by chitosan film $(2 \%)$ and kept at room temperature for one week [38].

\subsubsection{Production of chitosan microparticle.}

Chitosan microparticles were prepared [1] with slight modifications where $2 \%(\mathrm{w} / \mathrm{v})$ chitosan in $1 \%(\mathrm{v} / \mathrm{v})$ acetic acid solution was used and no carboxymethyl cellulose was used, and $25 \mathrm{~mL}$ of $1 \%$ Tripolyphosphate (TPP) solution was added dropwise to $25 \mathrm{~mL}$ of $2 \%$ chitosan solution. It was subjected to sonication and then centrifuged, the pellet was washed thrice with distilled water and lyophilized. Lyophilized chitosan microparticles were observed under a scanning electron microscope (XL 30 series, Jeol Tokyo, Japan) [39].

\subsubsection{Antifungal activity of chitosan microparticle.}

Agar plug of $5 \mathrm{~mm}$ plant pathogen Fusarium sp., Aspergillus sp., and Mucor sp. were placed on one end of the Rose Bengal agar plates. Agar well of $5 \mathrm{~mm}$ was punched with the help of a sterile gel puncher. Then $20 \mu \mathrm{l}$ of $2 \%$ chitosan nanoparticles were loaded into the well and incubated for $72-84 \mathrm{~h}$.

\section{Results and Discussion}

In the present work, a creamy white form of chitosan was obtained from the deacetylation of shrimp shell derived chitin. Source of commercial chitosan are shrimp, crab, 
lobster, and fungi chitin in different countries [40, 41, 1]. Chitosan yield from chitin was $45.2 \%$, moisture content $1.5 \%$, ash content was $1.21 \%$. Water binding capacity (WBC) and fat binding capacity (FBC) were $601.11 \%$ and $441.07 \%$, respectively (Table 1). The yield and moisture content were similar to an earlier report earlier [42, 43]. The moisture content of chitosan powder was well below the prescribed limit of $10 \%$ by KFDA (1995)[44]. In the present work, the ash content of chitosan was $1.21 \%$. This was substantiated by $1.18 \%$ for commercial chitosan [29]. Chitosan samples had low ash content (1.20\%), evidence of effective demineralization [45].

Table 1. Physio-chemical and functional properties of chitosan.

\begin{tabular}{c|c|c|c|c|c} 
Chitosan Yield (\%) & Moisture (\%) & Ash Content (\%) & Solubility in 1\% Acetic Acid & FBC (\%) & WBC (\%) \\
\hline 45.2 & 1.5 & 1.21 & Soluble & 441.07 & 601.11
\end{tabular}

$83.23 \%$. of the degree of deacetylation (DD) of chitosan was achieved. DD depends on chemicals of choice for preparation and normally ranges between $30 \%$ and 95\%[46]. Puvvada et al.[41] reported $85 \%$ of the degree of deacetylation in chitosan extracted from exoskeleton of Triopslongi caudatus and Triopscan criformis specimens. In the present study, the FT-IR spectrum for standard chitosan was compared [42]. Increased degree of deacetylation was seen as the band $1655 \mathrm{~cm}^{-1}(>\mathrm{C}=\mathrm{O})$ showed a change, where there was a shift between 1500 and $1750 \mathrm{~cm}^{-1}$, and a notable shape difference was observed between 3000 and $3500 \mathrm{~cm}^{-1}$ bands too. $1026 \mathrm{~cm}^{-1}$ of pure chitosan represents $-\mathrm{NH} 2$ of glucosamine's $\mathrm{C} 2$ position. For -NH2, a peak was seen at $1018.41 \mathrm{~cm}^{-1}$ (Figure 1). $1377 \mathrm{~cm}^{-1}$ was representing $-\mathrm{C}-\mathrm{O}$ stretching of a primary alcoholic group $(-\mathrm{CH} 2-\mathrm{OH})$. Absorbance bands observed at 3363.56, 2883.58, 1562.34, 1377.38, 1018.41, indicated the $\mathrm{N}-\mathrm{H}$ stretching, $\mathrm{CH}$ stretching, amide II stretching, asymmetric $\mathrm{CH} 2$ stretching and $\mathrm{C}=\mathrm{O}$ stretching respectively for the extracted chitosan (Figure 1) [42]. A larger peak at $1552 \mathrm{~cm}^{-1}$ was suggesting the deacetylation because deacetylation tends to decrease band at $1652 \mathrm{~cm}^{-1}$ [47].

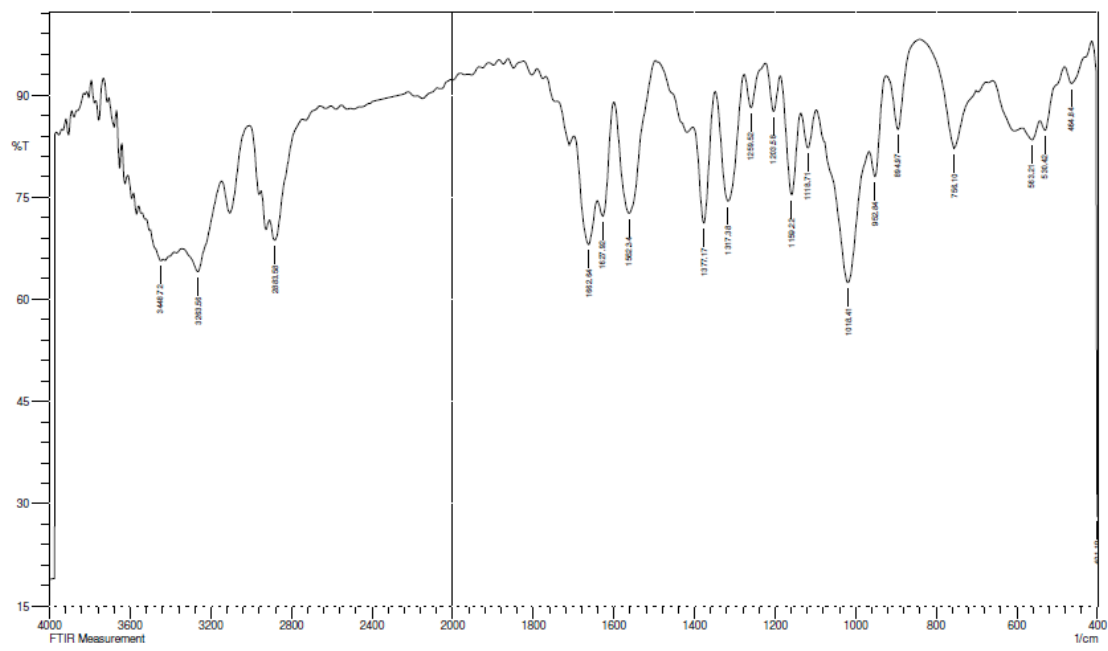

Figure 1. The FT-IR report of the chitosan extracted from the shrimp shell.

NMR spectroscopy was done to determine the degree of deacetylation [48]. Degrees of deacetylation was found to be seen as the DD signal from the methyl group, and hydrogen $\mathrm{H}$ 1 GlcNAc decreases because of the molar content of $\mathrm{N}$-acetylglucosamine in chitosan molecule goes down. The obtained spectra were used to confirm the successful modification of Cys on the main chain of chitosan. ${ }^{1} \mathrm{H}-\mathrm{NMR}$ spectra of extracted chitosan showed acetyl protons at $\delta$ $1.6 \mathrm{ppm}$. The spectra of chitosan tend to exhibit acetyl protons at $\delta 2.1 \mathrm{ppm}$ where they resonate 
at $\delta 3.2 \mathrm{ppm}$ is because of H-2 internal deacetylation [48]. H3-6 (ring) and H-2 (acetylated units) showed at $\delta 3.5$ and $4.1 \mathrm{ppm}$, respectively (Figure 2), which is on par with standard chitosan [48]. $\mathrm{H}-1$ of deacetylated units and $\mathrm{OH}$ resonate similarly to an earlier report (Figure 2) [48]. NMR analysis also confirmed the $83.23 \%$ deacetylation (Figure 2).

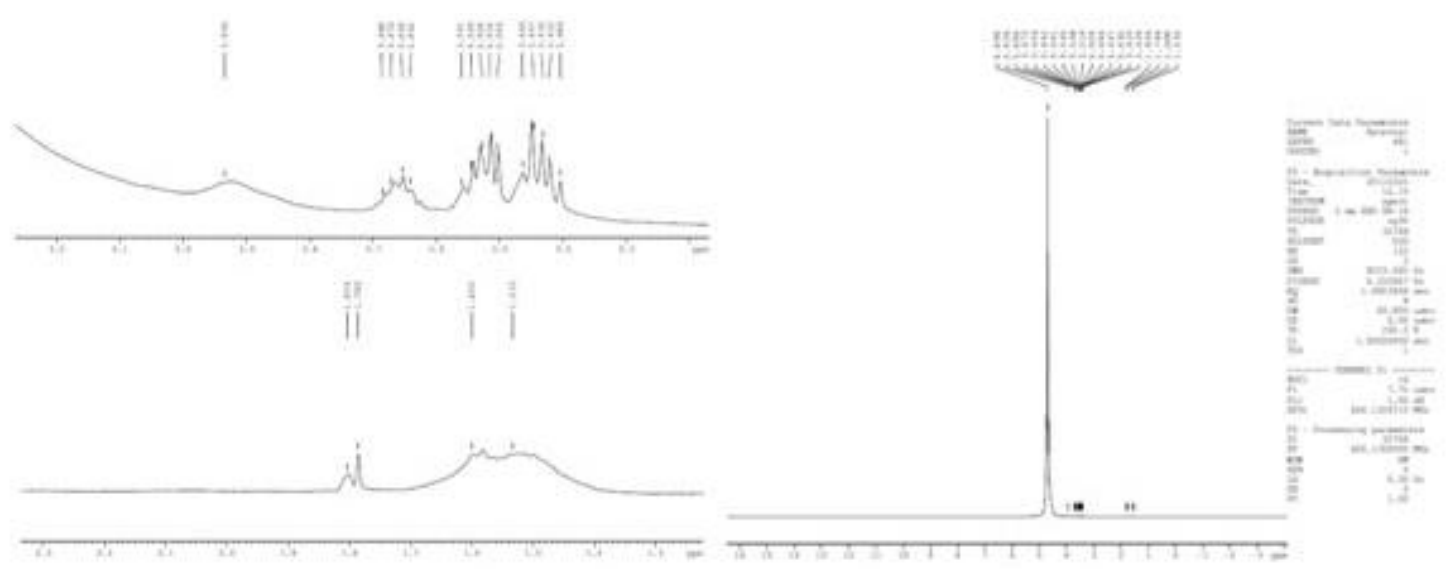

Figure 2. $1^{\mathrm{H}} \mathrm{NMR}$ spectra of chitosan extracted from shrimp shell chitin.

This study revealed that chitosan preparations of different concentrations have excellent enhancement of antibacterial activity against four strains (E. coli, Pseudomonas aeruginosa, Klebsiella pneumoniae, and Staphylococcus aureus) (Figure 3). Similarly, microorganisms' growth is inhibited by $1 \%$ chitosan and $0.0075 \%$, respectively $[49,50]$. In the current work, chitosan of $70 \mu \mathrm{g}$ and $80 \mu \mathrm{g}$ concentrations were shown to be a potent antibacterial agent against selected bacterial pathogens. This might be the polycationic nature of chitosan, which can easily bind to a negatively charged bacterial cell wall and creates impact.

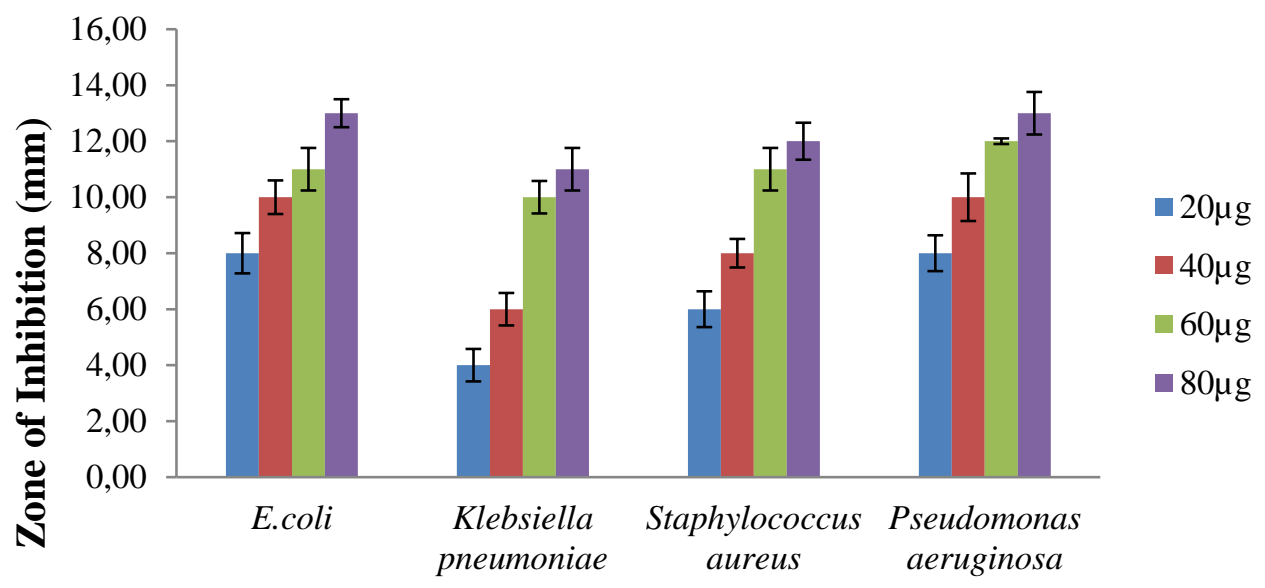

Figure 3. Antibacterial activity of chitosan against wound pathogens - Agar Well Diffusion Method.

Table 2. Minimal inhibitory concentration of chitosan.

\begin{tabular}{l|c|c|c|c|c}
\multirow{2}{*}{ S. No. } & \multirow{2}{*}{$\begin{array}{c}\text { Concentration of } \\
\text { chitosan }(\boldsymbol{\mu g})\end{array}$} & $\boldsymbol{E}$. coli & $\begin{array}{c}\text { Klebsiella } \\
\text { pneumoniae }\end{array}$ & Staphylococcus aureus & $\begin{array}{c}\text { Pseudomonas } \\
\text { aeruginosa }\end{array}$ \\
\cline { 3 - 6 } & Control & $0.5 \pm 0.10$ & $0.8 \pm 0.06$ & $0.6 \pm 0.05$ & $0.6 \pm 0.10$ \\
\hline 1 & 30 & $0.37 \pm 0.06$ & $0.60 \pm 0.10$ & $0.43 \pm 0.06$ & $0.40 \pm 0.10$ \\
\hline 2 & 40 & $0.28 \pm 0.03$ & $0.47 \pm 0.06$ & $0.36 \pm 0.05$ & $0.33 \pm 0.06$ \\
\hline 3 & 50 & $0.23 \pm 0.06$ & $0.40 \pm 0.10$ & $0.26 \pm 0.05$ & $0.33 \pm 0.15$ \\
\hline 5 & 60 & $0.17 \pm 0.06$ & $0.26 \pm 0.05$ & $0.13 \pm 0.06$ & $0.16 \pm 0.05$ \\
\hline 7 & 70 & $0.08 \pm 0.02$ & $0.17 \pm 0.12$ & $0.07 \pm 0.05$ & $0.08 \pm 0.01$ \\
\hline & 80 & $0.01 \pm 0.01$ & $0.02 \pm 0.12$ & $0.04 \pm 0.02$ & $0.01 \pm 0.01$
\end{tabular}


The minimal inhibitory concentration of chitosan was determined by the colorimetric method. After incubation, the optical density was measured. The $70 \mu \mathrm{g}$ of chitosan showed decreased OD value in all selected pathogens that indicated the reduction of bacterial growth. Among the 30, 40, 50, 60, 70, and $80 \mu \mathrm{g}$ concentration of chitosan, the minimal inhibitory concentration of chitosan was $70 \mu \mathrm{g}$ because of maximal bacterial growth reduction (compared with blank broth) (Table 2).

The minimum bacterial count was the lowest concentration that will inhibit the viable growth of microorganisms. $75 \mu \mathrm{g}$ of chitosan reduced all bacterial pathogens growth (tested) in the Nutrient agar plate (Table 3).

Table 3. Minimum Bacterial Count (MBC) using counting of surviving cells on the agar plate.

\begin{tabular}{l|c|c|c|c|c|c}
\multirow{2}{*}{ Microorganisms } & \multicolumn{7}{|c}{ Concentration of chitosan $(\boldsymbol{\mu g} / \mathbf{m l})$} \\
\cline { 2 - 7 } & $\mathbf{6 0}$ & $\mathbf{6 5}$ & $\mathbf{7 0}$ & $\mathbf{7 5}$ & $\mathbf{8 0}$ & $\mathbf{8 5}$ \\
\hline E. coli & + & - & - & - & - & - \\
\hline Klebsiella pneumonia & +++ & + & - & - & - & - \\
\hline Staphylococcus aureus & +++ & ++ & + & - & - & - \\
\hline Pseudomonas aeruginosa & ++ & + & - & - & - & - \\
+ Indicate the presence of bacterial growth; - Indicate the absence of bacterial growth.
\end{tabular}

$2 \%$ chitosan was shown to be a fungicide against the fungal pathogen - Fusarium sp., Aspergillus sp., and Mucor sp., (Table 4). Antimicrobial properties of chitosan can be applied to protect plants from plant pathogens [51]. Chitosan has the tendency to permeabilize the plasma membrane of fungi and leaks out protein, which was studied more pathogenic fungi [52].

Table 4. Antifungal activity of chitosan.

\begin{tabular}{l|l|l} 
Concentration of chitosan (\%) & Fungal pathogens & Inhibition ratio (\%) \\
\hline \multirow{4}{*}{0.5} & Fusarium $s p$. & 46.1 \\
\cline { 2 - 3 } & Mucor $s p$. & 12.5 \\
\cline { 2 - 3 } & Aspergillus $s p$. & 41.5 \\
\hline \multirow{4}{*}{1.5} & Fusarium $s p$. & 52.3 \\
\cline { 2 - 3 } & Mucor $s p$. & 35 \\
\cline { 2 - 3 } & Aspergillus $s p$. & 50.8 \\
\hline \multirow{3}{*}{2} & Fusarium $s p$. & 72.3 \\
\cline { 2 - 3 } & Mucor $s p$. & 40 \\
\cline { 2 - 3 } & Aspergillus $s p$. & 69.2 \\
\hline & Fusarium $s p$. & 92.3 \\
\cline { 2 - 3 } & Mucor $s p$. & 75 \\
\cline { 2 - 3 } & Aspergillus $s p$. & 76.9
\end{tabular}

Table 5. Effect of clarifying agents on the turbidity of grape juice.

\begin{tabular}{l|l|l|l|l}
\multirow{2}{*}{ Time (Minutes) } & \multirow{2}{*}{ Control } & \multicolumn{4}{|c}{ Chitosan concentration Optical Density $(\mathbf{5 4 0} \mathbf{~ n m})$} \\
\cline { 3 - 5 } & & $\mathbf{1 \%}$ & $\mathbf{1 . 5 \%}$ & $\mathbf{2 \%}$ \\
\hline 30 & 1.45 & 1.20 & 0.89 & 0.91 \\
\hline 60 & 1.45 & 1.04 & 0.61 & 0.62 \\
\hline 90 & 1.45 & 0.91 & 0.49 & 0.50
\end{tabular}

The effect on grape juice is illustrated in Table 5. A fall in the turbidity of the grape juices was noted after the addition of chitosan added juice (Figure 4b). After 30 minutes of the addition of a $1 \%$ chitosan solution, grape juice showed a turbidity value of 1.2 , followed by 1.04 after 60 minutes and 0.91 after 90 minutes. Similarly, after 30 minutes of addition of $1.5 \%$ chitosan solution to grape juice, a turbidity value of 0.89 was noticed, followed by 0.61 after 60 minutes and 0.49 after 90 minutes. After 30 minutes of the addition of $2 \%$ chitosan solution to grape juice, a turbidity value of 0.91 was noticed, followed by 0.62 after 60 min and 0.50 after $90 \mathrm{~min}$. The OD values $(0.91,0.62,0.50)$ after $30,60,90 \mathrm{~min}$ for a $2 \%$ concentration of 
chitosan showed increased luminosity with increasing time duration. The results indicated the effective clarification effect on grape juices by chitosan in the concentrations of $2 \%$.

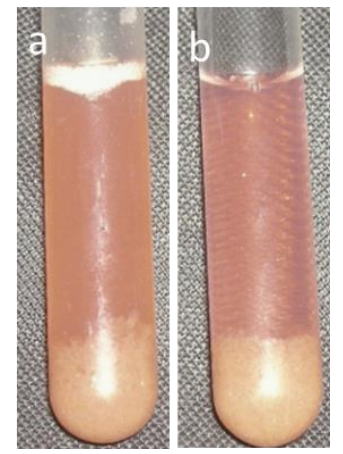

Figure 4. Effect of chitosan on grape juice a) control b) chitosan treated.

The effect on the $\mathrm{pH}$ of grape juice is seen in Figure 5. The $\mathrm{pH}$ was greatly altered by the addition of chitosan during the storage time. The $\mathrm{pH}$ was increasing towards acidity significantly concentration increases where the initial value was 3.28. After 14 days, $2 \%$ chitosan concentration showed a $\mathrm{pH}$ value of up to 4.5. After 21 days, $2 \%$ chitosan resulted in a relatively high $\mathrm{pH}$ value of 4.8 . In $1.5 \%$ chitosan concentration, $\mathrm{pH}$ values of $3.9,4.3,4.5$ were observed after 7, 14, 21 days. In $1 \%$ chitosan concentration, $\mathrm{pH}$ values of 3.3, 3.9, 4.1 were recorded after 7, 14, 21 days, respectively. The $\mathrm{pH}$ increase is reported as the concentration of chitosan increases where the $\mathrm{pH}$ reaches to 3.71 in apple juice [53]. Chitosan has been reported to be a good clarifier of various juices [54].

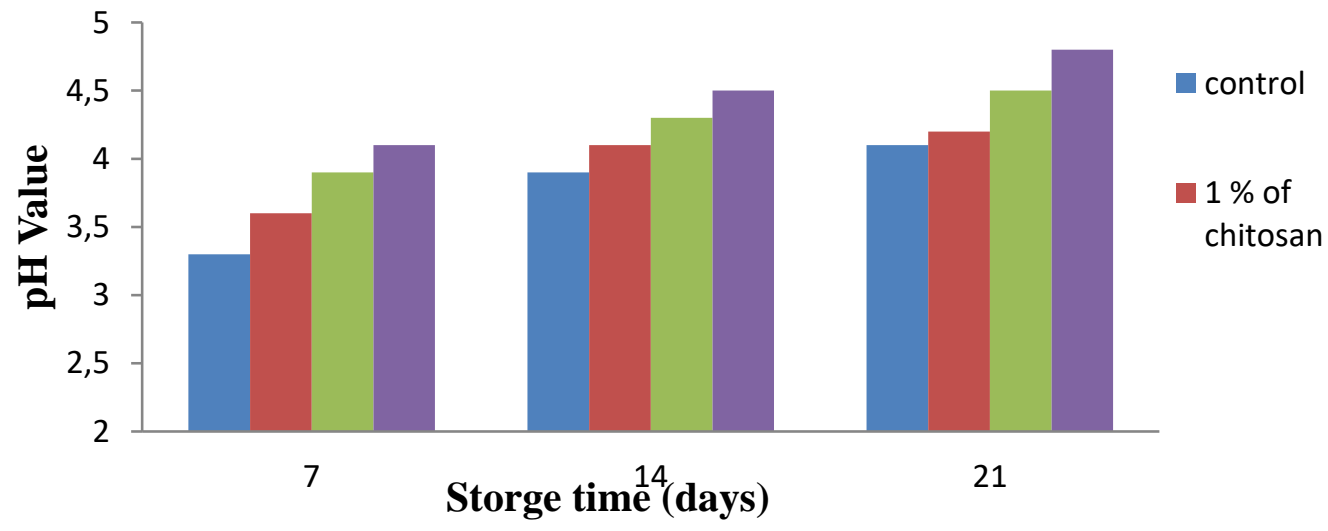

Figure 5. Effect of chitosan on $\mathrm{pH}$ of grape juice at different times.

Total count of microbes, i.e., both the bacteria and yeast, were reduced during storage of juice at $4{ }^{\circ} \mathrm{C}$ for 21 days (Table 6 ). Much inhibition exhibited by $2 \%$ chitosan. Antimicrobial activity and clarification effect of $2 \%$ chitosan could be used as an excellent fruit juice preservative. Chitosan showed a good preservative effect in juices [53], where it may absorb nutrients of bacteria and make it unavailable [55].

Table 6. Change of microbial count of grape juice with added chitosan during storage at $4{ }^{\circ} \mathrm{C}$ for 21 days.

\begin{tabular}{l|l|l|l|l|l}
\multirow{2}{*}{ Microorganisms } & \multirow{2}{*}{ Storage days } & \multirow{2}{*}{ Control $(\mathbf{C F U} / \mathbf{m l})$} & \multicolumn{3}{|l}{ Chitosan concentration $(\mathbf{C F U} / \mathbf{m l})$} \\
\cline { 4 - 6 } & & & $\mathbf{1 \%}$ & $\mathbf{1 . 5 \%}$ & $\mathbf{2 \%}$ \\
\hline \multirow{3}{*}{ Total bacteria } & 0 & $4 \times 10^{2}$ & $2.5 \times 10^{2}$ & $1 \times 10^{2}$ & $5.6 \times 10^{1}$ \\
\cline { 2 - 6 } & 5 & $31 \times 10^{3}$ & $50 \times 10^{2}$ & $14 \times 10^{2}$ & $3 \times 10^{2}$ \\
\cline { 2 - 6 } & 10 & $42 \times 10^{5}$ & $40 \times 10^{3}$ & $30 \times 10^{2}$ & $2 \times 10^{2}$ \\
\cline { 2 - 6 } & 15 & $52 \times 10^{6}$ & $42 \times 10^{5}$ & $24 \times 10^{4}$ & $9 \times 10^{2}$ \\
\cline { 2 - 6 } & 20 & $59 \times 10^{8}$ & $38 \times 10^{7}$ & $22 \times 10^{5}$ & $1.4 \times 10^{3}$ \\
\hline Yeast & 0 & $30 \times 10^{1}$ & $0.4 \times 10^{2}$ & $0.3 \times 10^{2}$ & $0.1 \times 10^{1}$
\end{tabular}




\begin{tabular}{l|l|l|l|l|l}
\multirow{2}{*}{ Microorganisms } & \multirow{2}{*}{ Storage days } & \multirow{2}{*}{ Control $(\mathbf{C F U} / \mathbf{m l})$} & \multicolumn{3}{|c}{ Chitosan concentration $(\mathbf{C F U} / \mathbf{m l})$} \\
\cline { 3 - 6 } & & $\mathbf{1 \%}$ & $\mathbf{1 . 5 \%}$ & $\mathbf{2 \%}$ \\
\cline { 3 - 6 } & 5 & $2.9 \times 10^{4}$ & $5.6 \times 10^{2}$ & $3.3 \times 10^{2}$ & $1.0 \times 10^{2}$ \\
\hline 10 & $42 \times 10^{6}$ & $38 \times 10^{3}$ & $24 \times 10^{2}$ & $4.0 \times 10^{2}$ \\
\hline 15 & $35 \times 10^{7}$ & $40 \times 10^{4}$ & $29 \times 10^{3}$ & $1.5 \times 10^{3}$ \\
\hline 20 & $38 \times 10^{8}$ & $44 \times 10^{5}$ & $15 \times 10^{4}$ & $10 \times 10^{3}$
\end{tabular}

The $1 \%, 1.5 \%$, and $2 \%$ of chitosan treated algal cells were counted microscopically after $12 \mathrm{~h}, 24 \mathrm{~h}, 48 \mathrm{~h}$, and $72 \mathrm{~h}$ of incubation (Table 7). After $72 \mathrm{~h}, 96.5 \%$ algal cell lysis was observed in the $2 \%$ chitosan treated sample (Figure 6 b). In a $1.5 \%$ chitosan treated sample, $94 \%$ algicidal activity was noted. In a $1 \%$ chitosan treated sample, $84 \%$ algicidal activity was observed. These results showed that the $2 \%$ chitosan solution to have an inhibitory action on algal growth. Chitosan at $2 \%$ concentration was shown to have high algicidal activity. The result was supported by Cuero and Lillehoj [56], who have shown that chitosan could prevent algae by increased aggregation.

After incubation, $2 \%$ chitosan treated seeds showed $90 \%$ germination, and that of 1.5 $\%, 1 \%$ chitosan inoculated seeds showed $83.3 \%$ and $63.3 \%$ germination after 7 days of sowing, and in control, only $56.6 \%$ germination was observed. The germination capacity of 2 $\%$ chitosan treated seeds was found to be $62.8 \%$ higher than the control seeds. $2 \%$ chitosan promoted higher germination percentage than other chitosan concentrations ( $1 \%$ and $1.5 \%$ ) (Table 8). Peanut with chitosan showed an increase in germination percentage [57] and also improved wheat seedlings [58].

Table 7. Algicidal activity of chitosan.

\begin{tabular}{l|c|c} 
Concentration of chitosan (\%) & Time (hrs) & Algicidal activity (\%) \\
\hline \multirow{4}{*}{1} & 12 & 31.4 \\
\cline { 2 - 3 } & 24 & 42.85 \\
\cline { 2 - 3 } & 48 & 63.4 \\
\cline { 2 - 3 } & 72 & 94 \\
\hline \multirow{4}{*}{1.5} & 12 & 38.2 \\
\cline { 2 - 3 } & 24 & 52 \\
\cline { 2 - 3 } & 48 & 68.6 \\
\cline { 2 - 3 } & 72 & 84.7 \\
\hline \multirow{4}{*}{2} & 12 & 50.9 \\
\cline { 2 - 3 } & 24 & 63.4 \\
\cline { 2 - 3 } & 48 & 81.4 \\
\cline { 2 - 3 } & 72 & 96.5
\end{tabular}

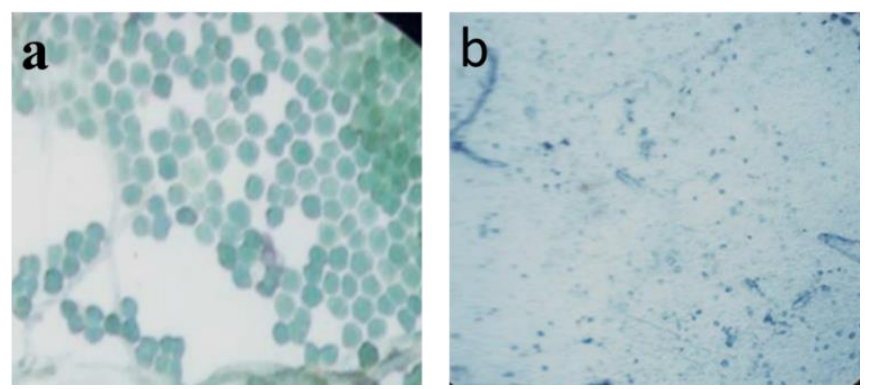

Figure 6. Microscopic observation of the algicidal activity of chitosan against Chlorella sp (magnification at $45 x)$ a) untreated and b) treated with $2 \%$ chitosan

Table 8. Effect of concentration of chitosan on seed germination

\begin{tabular}{l|c|c|c} 
S.No & Concentration of chitosan (\%) & Germination (\%) & Control (\%) \\
\hline 1 & 2 & 90 & 56.6 \\
\hline 2 & 1.5 & 83.3 & 56.6 \\
\hline 3 & 1 & 63.3 & 56.6
\end{tabular}


Figure 7 shows a prepared chitosan film. These films had inhibitory activity against Salmonella sp and Escherichia coli after $24 \mathrm{~h}$ of incubation. Both the $1 \%$ and $2 \%$ chitosan film showed maximal inhibition against Salmonella sp. organism, followed by Escherichia coli (Table 9).
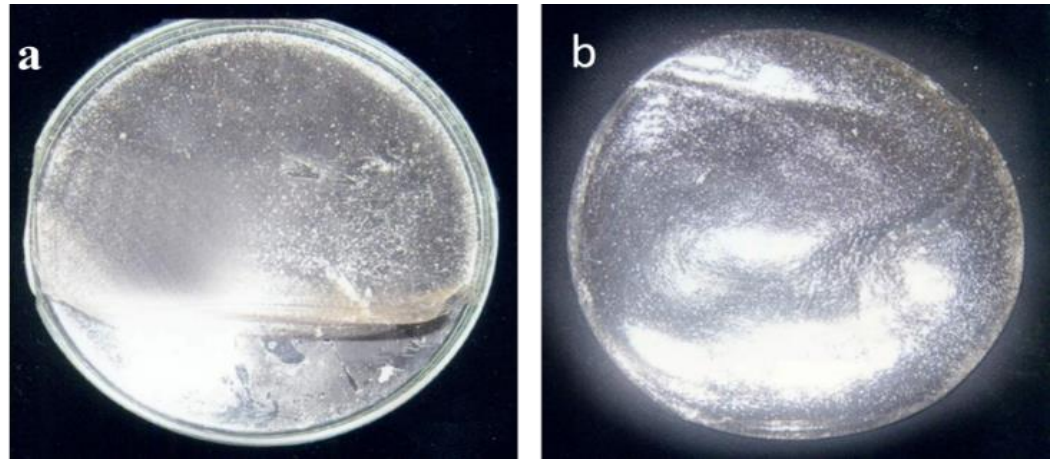

Figure 7. Chitosan film a) made using $1 \%$ b) chitosan film $2 \%$

In order to check the antifungal activity of chitosan film, fungal pathogen Aspergillus sp. was used in the present study. Antifungal activity of chitosan film showed $10 \mathrm{~mm}$ inhibition in $1 \%$ concentration of chitosan film against Aspergillus sp. $2 \%$ of chitosan film showed a 30 mm zone of inhibition against Aspergillus sp. There was no inhibition observed in the control film without chitosan (Table 9). The results showed that $2 \%$ of chitosan film has effectively inhibited the growth of the fungal pathogen. So, it could be used as an excellent wrapping material for food products or vegetables and fruits.

Table 9. Antimicrobial activity of chitosan film

\begin{tabular}{l|l|l} 
Chitosan film & Microorganisms & Zone of inhibition $(\mathbf{m m})$ \\
\hline \multirow{3}{*}{$1 \%$} & Escherichia coli & 5 \\
\cline { 2 - 3 } & Salmonella sp. & 6 \\
\cline { 2 - 3 } & Aspergillus sp. & 10 \\
\hline \multirow{3}{*}{$2 \%$} & Escherichia coli & 7 \\
\cline { 2 - 3 } & Salmonella sp. & 9 \\
\cline { 2 - 3 } & Aspergillus sp. & 30
\end{tabular}

Chitosan film extended the shelf life of tomato. After 7 days of incubation, the chitosan wrapped tomatoes showed no signs of spoilage symptoms (Figure 8 a- d). But, the control fruit showed fungal infection symptoms and shrinkage, indicating fruit spoilage. The experimental set, which was wrapped in chitosan film, was unaffected and looked fresh without any sign of spoilage even after seven days (Table 10). The application of chitosan was experimentally proven through the maintenance of vegetable quality and extended shelf life of tomato.
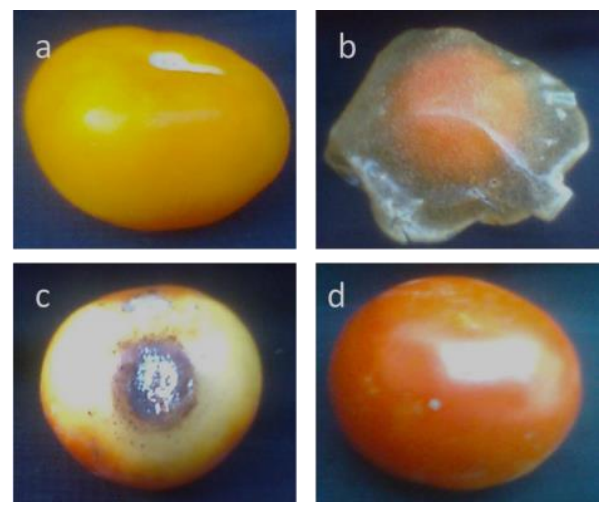

Figure 8. Chitosan films as wrappers a) unwrapped tomato (day 0) b) wrapped tomato (day 0) c) unwrapped tomato (day 7) d) wrapped tomato (day 7). 
Table 10. Tomato preservation with chitosan film.

\begin{tabular}{l|l|c|c|c}
\multirow{2}{*}{ S. No. } & \multicolumn{2}{|c|}{ Sample } & \multicolumn{3}{c}{ Days of storage } \\
\cline { 3 - 5 } & & $\mathbf{2}$ & $\mathbf{4}$ & $\mathbf{7}$ \\
\hline 1 & Control & Started to ripe & Ripe and skin shrinkage & Symptoms of rottening \\
\hline 2 & Chitosan film wrapped & Unchanged & Unchanged & Unchanged
\end{tabular}

Chitosan microparticles of size around $100 \mu \mathrm{m}$ with a smooth surface (Figure 9) were made using Tripolyphosphate (TPP). A similar result was obtained [1, 45] and reported nonsmooth surfaced chitosan nanoparticles. There are reports where $\mathrm{BaCl}_{2}$ induced chitosan to form nanoparticle, and it was used for drug delivery, SPIONs coating for heavy metal removal, and drug carrier [59 - 63]. Antifungal activity was observed against three fungal pathogens used in this study. The antifungal activity in $20 \mu \mathrm{l}$ of $2 \%$ chitosan nanoparticles against Fusarium sp. was $81.3 \%$, Aspergillus sp. was $89.2 \%$ and that against Mucor sp. was $78.6 \%$ (Figure 10). Chitosan-based nanofibers loaded with herbal extract have been developed as wound dressing materials, which would be an effective one [64]. Cinnamaldehyde loaded chitosan nanoparticles are also produced, and it was exhibiting good antimicrobial activity [65]. Even more, these chitosan have applications in dye removal too [66].

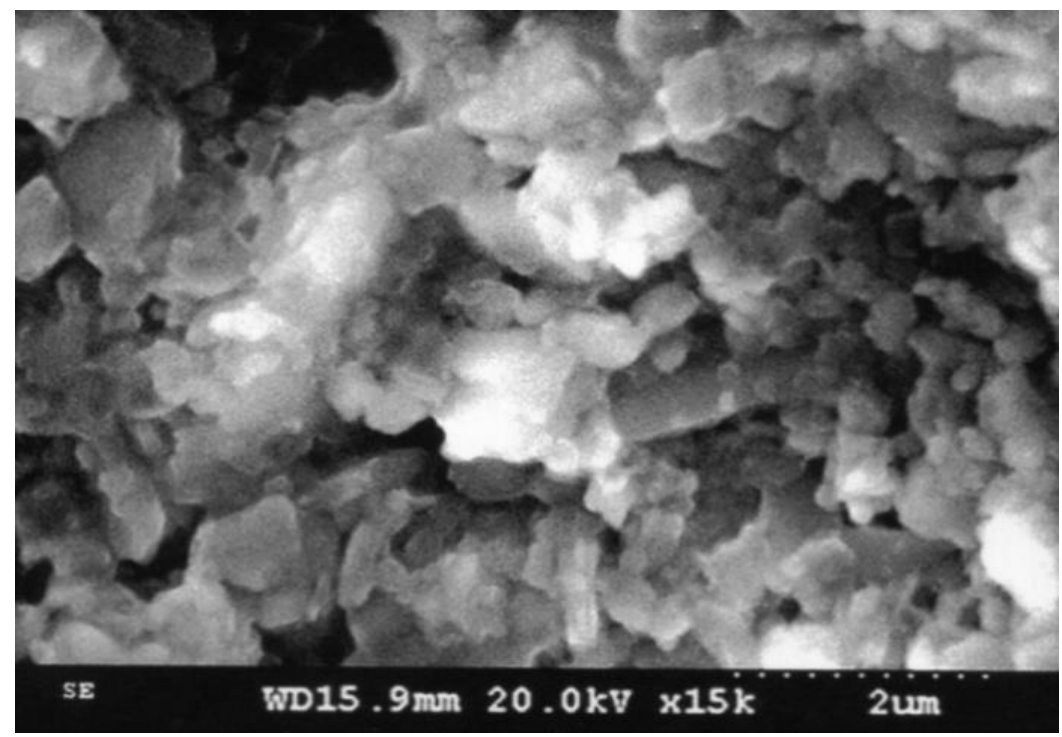

Figure 9. Scanning electron microscopy analysis chitosan microparticle.
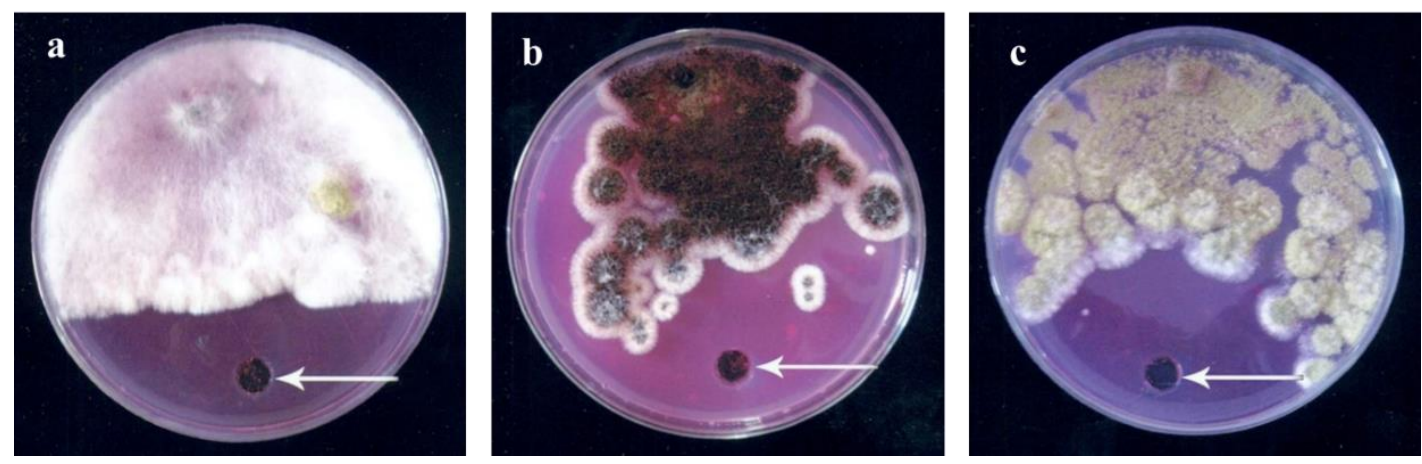

Figure 10. Antifungal activity of chitosan microparticle (white arrow denotes the well added with nanoparticle) a) Fusarium sp b) Mucor sp c) Aspergillus sp.

\section{Conclusion}

In this study, chitosan was obtained from the chitin of shrimp waste, and the yield of chitosan was $45.2 \%$. The degree of deacetylation (DD) was $83.23 \%$. The obtained chitosan was found to be effective against wound pathogens and also phytopathogenic fungi. It was showing 
a good preservative activity in grape juice. The chitosan film showed inhibitory activity against Salmonella and Escherichia coli. 2\% of chitosan film has effectively inhibited the growth of the fungal pathogen. Chitosan film was having a good moisture effect and helped in seed germination. It was also extended the shelf life of tomato at room temperature. Chitosan was able to form microparticles around $100 \mu \mathrm{m}$, and it had antifungal activity.

\section{Funding}

This research received no external funding.

\section{Acknowledgments}

\section{The first author wants to acknowledge her students for their support.}

\section{Conflicts of Interest}

The authors declare no conflict of interest.

\section{References}

1. Samrot, A.V.; Akanksha, Jahnavi, T.; Padmanaban, S.; AnnPhilip, S.; Burman,U.; Rabel, A.M. Chelators influenced synthesis of chitosan-carboxymethyl cellulose microparticles for controlled drug delivery. Appl Nanosci. 2016, 6, 1219-1231, https://doi.org/10.1007/s13204-016-0536-9.

2. Saputra, K.A.; Angela, A.A.; Surya, R.; Gifsan,Y. Application of chitosan as preservatives on organic fruits. Asian J Food Agric Ind. 2009, 264-270.

3. Kumar,A.B.V.; Varadaraj,M.C.; Gowda, L.R.; Tharanathan, R.N. Characterization of chito-oligosaccharides prepared by chitosanolysis with th e aid of papain and pronase, and their bactericidal action against Bacillus cereus and Escherichia coli. Biochem J. 2005, 391, 167-175, https://doi.org/10.1042/BJ20050093.

4. Singla, A.K.; Chawla, M. Chitosan: Some pharmaceutical and biological aspects - An update. J Pharm Pharmacol. 2001, 53, 1047-1067, https://doi.org/10.1211/0022357011776441.

5. Ueno, H.; Mori, T.; Fujinaga, T. Topical formulations and wound healing applications of chitosan. Adv Drug Delivery Rev 2001, 52,105-115, https://doi.org/10.1016/s0169-409x(01)00189-2.

6. Takai, K.; Ohtsuka,T.; Senda, Y.; Nakao, M.; Yamamoto, K.; Matsuoka, J.; Hirai, Y. Antibacterial properties of antimicrobial finished textiles Products. Microbiol Immunol. 2002, 46, 75-81, https://doi.org/10.1111/j.1348-0421.2002.tb02661.x.

7. Doares, S.H.; Syrovets, T.; Weiler, E.W.; Ryan, C.A. Oligo galacturonides and chitosan activate plant defensive genes through the octadecanoid pathway. Proc Nat Acad Sci. 1995, 92, 4095-4098, https://doi.org/10.1073/pnas.92.10.4095.

8. Rhoades, J.; Roller, S. Antimicrobial actions of degraded and native chitosan against spoilage organisms in laboratory media and foods. Appl Environ Microbiol. 2000, 66, 80-86, https://doi.org/10.1128/aem.66.1.8086.2000.

9. Samrot, A.V.; Shobana, N.; Burman, U.; Philip, S.A.; Chandrasekaran, K. Utilization of crab shell derived chitosan for production of gallic acid loaded nanocomposites for drug delivery. J Pharm Sci Res. 2018, 10, 2169-2174.

10. Babel, S.; Kurniawan, T.A. Cr(VI) removal from synthetic wastewater using coconut shell charcoal and commercial activated carbon modified with oxidizing agents and/or chitosan. Chemosphere 2004, 54, 951967, https://doi.org/10.1016/j.chemosphere.2003.10.001.

11. Chirkov, S.N. The antiviral activity of chitosan. Appl Biochem Microbiol. 2002, 38, 1-8, https://doi.org/10.1023/A:1013206517442.

12. Fernandes, J.C.; Tavaria, F.K.; Soares, J.C.; Ramos, O.S.; Monteiro, M.J.; Pintado, M.E. Antimicrobial effects of chitosans and chito-oligosaccharides, upon Staphylococcus aureus and Escherichia coli, in food model systems. Food Microbiol. 2008, 25, 922-928, https://doi.org/10.1016/j.fm.2008.05.003.

13. Britto, D.; Campana, S.P.; Campana Filho, S.P.; Assis, O.B.G. Mechanical properties of N, N, N trimethylchitosan chloride films. Polimer Ciencia Technol. 2005, 15, 142-145.

14. Shahidi, F.; Synowiecki, J. Isolation and characterization of nutrients and value-added products from snow crab (Chionoecetes opilio) and shrimp (Pandalus borealis) processing discards. J Agri Food Chem. 1991, 39 (8), 1527-1532, https://doi.org/10.1021/jf00008a032.

15. Sanford, P.A.; Chitosan: Commercial uses and potential applications. In: Chitin and Chitosan - sources. Chemistry, Biochemistry, Physical Properties and Applications. Skjak, G.; Anthonsen, T.; Sanford, P. 
editors. London, UK: Elsevier; 1989, pp. 51-69.

16. Alburquenque, C.; Bucarey, S.A.; Neira Carrillo, A.; Urzua, B.; Hermosilla, G.; Tapia, C.V. Antifungal activity of low molecular weight chitosan against clinical isolates of Candida sp. Med Mycol. 2010, 48, 1018-1023, https://doi.org/10.3109/13693786.2010.486412.

17. Pal J.; Verma, H.O.; Munka, V.K.; Maurya, S.K.; Roy, D.; Kumar, J. Biological method of chitin extraction from shrimp waste an ecofriendly low cost technology and its advanced application. Int J Fish Aquatic Stud. 2014, 1, 104-107.

18. Abirami, S.; Nagarajan, D. Extraction of Chitin from Shrimp Shell Wastes by Using Bacillus licheniformis and Lactobacillus plantarum. Inter J Rec Res Aspects. 2018, 307-315.

19. Kurita, K.; Sugita, K.; Kodaira, N.; Hirakawa, M.;Yang, Y. Preparation and evaluation of trimethylated chitin as a versatile precursor for facile chemical modifications. Biomacromole. 2005, 6, 1414-1418, https://doi.org/10.1021/bm049295p.

20. Qian, R.Q.; Glanville, R.W. Methods for purifying chitosan. US 2004/0118778 A1, 2005.

21. Domszy, J.G.; Roberts, G.A.F. Evaluation of infra red spectroscopic techniques for analysing chitosan. Macromolecular chemistry and Physics 2003, https://doi.org/10.1002/macp.200400355.

22. Kasaai, M.R. Determination of the degree of N-acetylation for chitin and chitosan by various NMR spectroscopy techniques - A review. Carbohydr Polym. 2010, 79, 801-810, https://doi.org/10.1016/j.carbpol.2009.10.051.

23. Black, C.A. Methods of Soil Analysis: Part I physical and mineralogical properties. American Society of Agronomy, Madison, Wisconsin, 1965.

24. Shah, M.I.; Masumb, M.; Rahmana, M.M.; Islam Mollab, M.A. Preparation of chitosan from shrimp shell and investigation of its properties. Int J Basic Appl Sci. 2011, 11, 116-130.

25. No, H.K.; Cho, Y.I.; Kim, H.R.; Meyers, S.P. Effective deacetylation of chitin under 72 conditions of 15 psi/121 ${ }^{\circ}$ C. J Agric Food Chem. 2000, 48, 2625-2627, https://doi.org/10.1021/jf9908421.

26. Watthanaphanit, A.; Supaphol, P.; Tamura, H.; Tokura, S.; Rujiravanit, R. Wet spun alginate/chitosan whiskers nanocomposite fibers: Preparation, characterization and release characteristic of the whiskers. Carbohydr Polym. 2010, 79, 738-746, https://doi.org/10.1016/j.carbpol.2009.09.031.

27. Perez, L.M.; Pavani, M.; Quaas, A.; Roco, A. Umbelliferone and scoparone are synthesised by lemon seedlings in the hypersensitive response against Alternaria alternata, Trichoderma harzianum and other elicitors. Fitopatologia 1994, 29, 94 -101.

28. Jones, N.R.; Barry, L.A.; Gavan, L.T.; Washington, J.A. Susceptibility tests: Microdilution and macrodilution broth procedures. In: Manual of Clinical Microbiology (Lennette E.H., A. Bellows, W.J Hausler and H.J Shadomy (eds.), 4th edn, American Society of Microbiology, Washington DC. Pp. 972-976; 1985.

29. Wang, S.L.; Lin, T.Y.; Yen, Y.H.; Liao, H.F.; Chen, Y.J. Bioconversion of shellfish chitin wastes for the production of Bacillus subtilis W118 chitinase. Carbohydr Res. 2006, 341, 2507-2515, https://doi.org/10.1016/j.carres.2006.06.027.

30. Oszmianski, J.; Wojdylo, A. Effects of various clarification treatments on phenolic compounds and color of apple juice. European Food Res Technol. 2007, 224, 755-762, https://doi.org/10.1007/s00217-006-0370-5.

31. APHA America Public Health Association, Standard Method of the Examination of Dairy Products.14th (ed.), A.P.H.A Inc Washington. D.C., U.S.A. 1984.

32. Bai, S.J.; Huang, L.P.; Su, J.Q.; Tian, T.; Zheng, T.L. Algicidal effects of a novel marine actinomycete on the toxic dinoflagellate Alexandrium tamarense. Curr Microbiol. 2011, 62, 1774-1781, https://doi.org/10.1007/s00284-011-9927-z .

33. Paulin, L.E.G.; Miranda Castro, S.P.; Moreno Martinez, E.; Lara Sagahon, A.V.; Torres Pacheco, I. Maize seed coatings and seedling sprayings with chitosan and hydrogen peroxide: their influence on some phenological and biochemical behaviors. J Zhejiang Univ Sci. 2013, 14, 87-96.

34. ISTA. International Rules of Seed Testing. International Seed Testing Association (ISTA), Edition, CH, Switzerland 2006.

35. Zeng, D.; Shi,Y. Preparation and application of a novel environmentally friendly organic seed coating for $\begin{array}{lllll}\text { Rice. American Eurasian } & \text { Agron. }\end{array}$ 19-25, https://doi.org/10.1002/jsfa.3700.

36. Pal, K.; Pal, S. Development of porous hydroxyapatite scaffolds. Mater Manufac Process. 2006, 21, 325328, https://doi.org/10.1080/10426910500464826.

37. Tripathi, S.; Mehrotra, G.K.; Dutta, P.K. Chitosan based antimicrobial films for food packaging applications. e-Polymers. 2008, 93, 1-7, https://doi.org/10.1515/epoly.2008.8.1.1082.

38. Tarafdar, A.; Biswas, G. Extraction of chitosan from prawn shell wastes and examination of its viable commercial applications. Int J Theoretical Appl Res Mechan Eng. 2013, 2, 17-24.

39. Silva, D.J.B.; Zuluaga, F.; Valencia, C.H. Evaluation of biocompatibility of chitosan films from the mycelium of Aspergillus niger in connective tissue of Rattus norvegicus. J Mol Genetics Med. 2015, 9.

40. Du, W.L.; Niu, S.S.; Xu, Y.L .; Xu, Z.R.; Fan, C.L. Antibacterial activity of chitosan tripolyphosphate nanoparticles loaded with various metal ions. Carbohydr Polym. 2009, 75, 385-389, https://doi.org/10.1016/j.carbpol.2008.07.039. 
41. Al Sagheer, F.A.; Al Sughayer, M.A.; Muslim, S.; Elsabee, M.Z. Extraction and characterization of chitin and chitosan from marine sources in Arabian Gulf. Carbohydr Polym. 2009, 77, 410-419, https://doi.org/10.1016/j.carbpol.2009.01.032.

42. Puvvada, Y.S.; Vankayalapati, S.; Sukhavasi, S. Extraction of chitin from chitosan from exoskeleton of shrimp for application in the pharmaceutical industry. Int Curr Pharmaceut J. 2012, 1, 258-263, https://doi.org/10.3329/icpj.v1i9.11616.

43. Tajik, H.; Moradi, M.; Rohani, S.M.R.; Erfani, A.M.; Jalali, F.S.S. Preparation of chitosan from brine shrimp (Artemia urmiana) cyst shells and effects of different chemical processing sequences on the physicochemical and functional properties of the product. Molecule. 2008, 13, 1263-1274, https://doi.org/10.3390/molecules13061263.

44. KFDA, Food Additives Code, Seoul: Korea Food and Drug Administration. 1995. pp 449-451.

45. Islam, M.; Md Masum, S.; Rahman, M.M.; Molla, M.A.I.; Shaikh, A.A.; Roy, S.K. Preparation of chitosan from shrimp shell and investigation of its properties. Int J Basic Appl Sci. 2011, 11, 77-80.

46. Di Martino, A.; Sittinger, M.; Risbud, M.V. Biomaterials. Chitosan: a versatile biopolymer for orthopaedic tissue-engineering. Biomaterial. 2005, 26, 5983-5990, https://doi.org/10.1016/j.biomaterials.2005.03.016.

47. Bordi, F.;Cametti,; Paradossi, G. Dielectric behavior of polyelectrolyte solutions: The role of proton fluctuation. J Phys Chem. 1991, 95, 4883-4889, https://doi.org/10.1021/j100165a051.

48. Kasaai, M. A review of several reported procedures to determine the degree of N-acetylation for chitin and chitosan using infrared spectroscopy. Carbohydr Polym. 2008, 71, 497-508, https://doi.org/10.1016/j.carbpol.2007.07.009.

49. Darmadji, P.; Izumimoto, M. Effect of chitosan in meat preservation. Meat Sci. 1994, 38, 243-54, https://doi.org/10.1016/0309-1740(94)90114-7.

50. Simpson, B.K.; Gagne,' N.; Ashie, I.N.A.; Noroozi, E. Utilization of chitosan for preservation of raw shrimp. Food Biotechnol. 1997, 11, 25-44, https://doi.org/10.1080/08905439709549920.

51. Hadrami, A.I.; Adam, L.R.; Hadrami, I.E.; Daayf, F. Chitosan in Plant Protection. Mar Drug. 2010, 8, 968-987, https://doi.org/10.3390/md8040968.

52. Palma-Guerrero, J.; Jansson, H.B.; Salinas, J.; Lopez-Llorca, L.V. Effect of chitosan on hyphal growth and spore germination of plant pathogenic and biocontrol fungi. J Appl Microbiol. 2008. 104, 541-553, https://doi.org/10.1111/j.1365-2672.2007.03567.x.

53. Abd, A.J.; Niamah, A.K. Effect of chitosan on apple juice quality. Int J Agricul Food Sci. 2012, 2, 153-157.

54. Chatterjee, S.; Chatterjee, S.; Chatterjee, B.P.; Guha, A.K. Clarification of fruit juice with chitosan. Process Biochem. 2004, 39, 2229-2232, https://doi.org/10.1016/j.procbio.2003.11.024.

55. Knorr, D Recovery and utilization of chitin and chitosan in food processing waste management. Food Technol. 1991, 45, 114-122.

56. Cuero, R.G.; Lillehoj, E.B. N-carboxymethylchitosan: Algistatic and algicidal properties. Biotechnol Tech. 1990, 4, 275-280.

57. Zhou, Y.G.; Yang, Y.D.; Qi, Y.G.; Zhang, Z.M.; Wang, X.J.; Hu, X.J. Effects of chitosan on some physiological activity in germinating seed of peanut. J Peanut Sci. 2002, 31, 22-25.

58. Hameed, A.; Sheikh, M.A.; Hameed, A.; Farooq, T.; Basraq, S.M.A.; Jamil, A.Chitosan seed priming improves seed germination and seedling growth in wheat (Triticum aestivum L.) under osmotic stress induced by polyethylene glycol. Philipp Agric Scientist. 2014, 97, 294-299.

59. Shobana, N.; Kumar, P.S.; Raji, P.; Samrot, A.V. Utilization of crab shell-derived chitosan in nanoparticle synthesis for Curcumin delivery. Indian J Geo Marine Sci. 2019, 48, 1183-1188.

60. Samrot, A.V.; Shobana, N.; Kumar, S.S.; Narendrakumar, G. Production, optimization and characterisation of chitosanase of bacillus sp and its applications in nanotechnology. J Cluster Sci. 2019, 30, 607-620, https://doi.org/10.1007/s10876-019-01520-z.

61. Samrot, A.V.; Burman, U.; Ann Philip, S.; Shobana, N.; Chandrasekaran,K. Synthesis of curcumin loaded polymeric nanoparticles from crab shell derived chitosan for drug delivery. Informatics Med Unlocked 2018, 10, 159-182, https://doi.org/10.1016/j.imu.2017.12.010.

62. Samrot, A.V.; Shobana, N.; Sruthi, D.P.; Sahithya, C.S. Utilization of chitosan coated superparamagnetic iron oxide nanoparticles for chromium removal. Appl Water Sci. 2018, 8, https://doi.org/10.2147/ijn.s214236.

63. Samrot, A.V.; SenthilKumar, P.; Bhushan, S.; Kurup, R.; Burman, U.; Ann Philip, S.; Padmanaban, S. Sodium Tri Poly Phosphate Mediated Synthesis of Curcumin Loaded Chitosan-Carboxymethyl Cellulose Microparticles for Drug Delivery. Int J Pharmacog Phytochem Res. 2017, 9, 694-702, https://doi.org/10.25258/phyto.v9i5.8151.

64. Amanzadi, B; Mirzaei, E.; Hassanzadeh, G.; Mahdaviani, P.; Boroumand, S.; Abdollah, M; Abdolghaffari, A.M.; Majidi, R.F. Chitosan-based layered nanofibers loaded with herbal extract as wound-dressing materials on wound model studies. Biointerface Research in Applied Chemistry. 2019, 9 (4), 3979 - 3986. https://doi.org/10.33263/BRIAC94.979986.

65. Soto-Chilaca, G.A.; Mejía-Garibay, B.; Navarro-Amador, R.; Ramírez-Corona, N.; Palou, E.; López-Malo, A. Cinnamaldehyde-loaded chitosan nanoparticles: characterization and antimicrobial activity. Biointerface Research in Applied Chemistry. 2019, 9(4), 4060 - 4065. 
66. Ali, S.F.A.; Gad, E.S.; Investigation of an adsorbent based on novel starch/chitosan nanocomposite in extraction of indigo carmine dye from aqueous solutions. Biointerface Research in Applied Chemistry. 2020, 10(3), 5556 - 5563. https://doi.org/10.33263/BRIAC103.556563 https://doi.org/10.33263/BRIAC94.060065 